\title{
Determining the Misunderstandings of Physics and Science Teacher Candidates about the Events Related to the Buoyancy Force
}

\author{
${ }^{1 *}$ Ersin Bozkurt, ${ }^{2}$ Fatih S. Yıldırım \\ ${ }^{1}$ Necmettin Erbakan University, Ahmet Keleşoğlu Faculty of Education- Turkey \\ ${ }^{2}$ Akdeniz University. Faculty of Education- Turkey
}

\begin{abstract}
The purpose of the study is to explore how pre-service teachers perceive buoyancy force affecting an object in a liquid and identify their misunderstandings and misconceptions. Pre-service teachers were interviewed to reveal their understandings of an object' floating, suspending and sinking in a liquid. In addition, they were asked about how an object-given its featuresmoved when it is provided with an external force and when it is released. The so-called circumstances were questioned in a different planet context. For this aim, focused group interview method was used. Work-group of the research was formed with senior year physics teaching department students and senior year sciencs teaching department students studying at two different university in Turkey. Seven focused groups were formed and video recorded during the interval. Each focused group comprised of six pre-service teachers. It was found out pre-service teachers have common misunderstanding and misconceptions. In this study, unlike similar studies, it was determined that pre-service teachers had misunderstandings about the movement that a floating object would take after it was sunk and released. In addition, it has been determined that pre-service teachers have some misunderstandings when the events related to the buoyancy force are repeated on a planet where the gravitational acceleration is different. At the end of the study, suggestions were made to eliminate these conceptual misunderstandings.
\end{abstract}

Keywords: Physics education, science education, students' misunderstandings in physics, computer simulations, miscopentions, buoyancy force.

\section{INTRODUCTION}

Human beings interact with their environments as of birth, and as a result they develop concepts on one hand, while they learn the names of these concepts by adding them to their vocabulary on the other. These learnings turn into new learnings as a result of relationships established in the mind, and they find meaning. This process enables sometimes producing new knowledge, and sometimes interpreting the existing knowledge, and continues lifelong.

Newly learnt concepts are explained with concepts learnt or developed before. This indicates that, concepts are the materials that run the thinking process of human beings, and unknown concepts are tried to be explained with the known (Hewson, \& Hewson, 1983). Consequently, new concepts are constructed, and this process continues lifelong. The concepts individuals have affect their point of view of the world.

In the human mind, concepts are developed using some mental processes. One of the most important of these processes is the generalization process. Generalization is defined as reaching at a general principle by deducing from experiments designed before. One of the reasons for misconceptions is resulted from generalization. Especially, some generalizations used in some books to develop concepts are incorrect. A generalization that includes a sample, which shouldn't be in the category, in a category is faulty. This kind of fault is called as over-generalization. A generalization that excludes a concept that should be in the category is also faulty. This type of fault is called under-generalization. In short, over-generalization results in exceeding the meaning of a concept, and undergeneralization results in narrowing of the meaning.

\section{A. Stability of misconceptions with conceptual difficulties with traditional instruction}

Many research on physics education have revealed that students have difficulties in physics, and they have many misconceptions in many different subjects of physics (Özsevgeç \& Çepni, 2006; Şahin \& Çepni, 2011; Yin, Tomita, \& Shavelson, 2008). The main reason for misconceptions of students is their previous knowledge and epistemological beliefs they have

Corresponding Author e-mail: ebozkurt@erbakan.edu.tr https://orcid.org/xxxxxxxxxxxxxxxxxxxx

How to cite this article: Bozkurt E, Yıldırım FS (2022). Determining the Misunderstandings of Physics and Science Teacher Candidates about the Events Related to the Buoyancy Force. Pegem Journal of Education and Instruction, Vol. 12, No. 1, 2022, 222-231

Source of support: Nil

Conflict of interest: None.

DOI: $10.47750 /$ pegegog.12.01.23

Received: 23.09.2021

Accepted: 21.12.2021 Publication: 01.01.2022 
about the events and concepts in physics (Hammer, 1995; Hammer, 1994; Zeineddin, \& Abd-El-Khalick, 2010; Linder, 1992; Lising, \& Elby, 2005)

Misconceptions in physic subjects lead to misunderstandings. If students have misconceptions in one or more of the concepts they will use to explain a physical event, they will have misunderstandings while they explain the concepts about the event, or inter-conceptual relations.

A teacher who teaches physics with traditional teaching methods will be ineffective while they teach their students to associate the concepts they newly structure with daily events. With this method, the conceptual difficulties students have before teaching, continue the same way after the teaching. Including the laboratory studies, these conceptual difficulties will continue without much change. In order to realize meaningful learning, and eliminate conceptual difficulties, some methods and techniques need to developed. There are many teaching methods used for this purpose (Hung \& Jonassen, 2006; Tural, Akdeniz, \& Alev, 2010; Şahin \& Çepni, 2011; Eryilmaz, 2002).

There are many methods for preventing or correcting misconceptions. Most important of these are modelling and conceptual change texts. However, incorrect modelling can also result in misconceptions. For this reason, the model should be designed so that it won't cause misconceptions in the context it is dealt.

\section{B. Conceptual errors related to buoyancy in liquids}

The purpose of the present research is present how university students understand events related to buoyancy they learn in general physics course, and this way reveal any misconceptions of buoyancy students have. The reasons forming the starting point of the present research are listed below in accordance with literature review above.

One of the most important of these reasons is the incorrect definitions of buoyancy in liquids in some textbooks. The general definition is:

"In a liquid, buoyancy affecting the object is equal to the

weight of the liquid overflowed by the object."

The expression "liquid overflowed" in the definition above is stated as "displaced liquid" in some of the books. As buoyancy is a force, it is a vector quantity. Similarly, as the weight of overflowed or displaced liquid is a force, it is a vector quantity as well. The expression 'buoyancy is equal to the weight of the overflowed liquid' refers that these two forces are equal. For these two similar vectors to be equal, the intensities and the directions of the vectors should be the same. However, the directions of two forces are opposite to each other.

One of the other reasons for conducting the present research is that, buoyancy in liquids is studied in textbooks with only one aspect. As teachers follow these source books, students can only evaluate the subject from one aspect.
This can result in that students generalize what they learn about the buoyancy in liquids to other events related to other buoyancies. In general, as textbooks give information about buoyancy in liquids, the states on objects floating in a still liquid, and sunk to bottom of the vessel containing the liquid are given. Dropping the object into a still liquid from free state and the movements of the objects in the liquid are not studied much. In this case, students generalize sinking, floating states of the objects as they are balanced in the liquid, to mobile states of the objects in the liquid. This results in contradiction in terms for students.

One of the other common mistakes in the textbooks is, even the definitions and information about the buoyancy in liquids are true, the concepts used in examples and problems for practice may be incorrect. For instance, one of the problems asks for the number of people of the same weight that can be on a boat without sinking the boat. For explanation, it was stated that the weight of the displaced water was equal to buoyancy. These kinds of mistakes are especially common in the online lecturing videos on the subject. Some online material, and some reference books even state that, buoyancy is greater than the weight of the object, which is still, sunk partially, and floating in the liquid. Some of the sample problems in source books and question banks in Turkey, are away from daily life problems most of the time. For this reason, students try to memorize the physics subjects and problems in order to succeed in the exams. For this reason, students may ignore the importance of physics in our daily lives, and perceive it just as a difficult course.

The present research tries to determine how senior year students of physics teaching and science teaching departments in two different universities perceive buoyancy in liquids related events. The research adopted focus group interview, which is a qualitative method. The answers obtained from the students were surprising and worrisome. Research findings revealed that, students have some misconceptions. The reasons for these misconceptions were tried to be found out during focus group interviews. At the end of the research, some samples and pre-prepared simulations were suggested for the use of teachers and students.

\section{Research Design}

\section{A. Purpose}

The purpose of the present research is investigating how physics and science teacher candidates perceive physical events related to buoyancy that affects an object in a liquid, and finding out their misunderstandings and misconceptions.

\section{B. Method}

The present research adopted focus group interview, which is a qualitative research method. This method was adopted in order to investigate and reveal student perceptions of buoyancy 
deeply. Six questions were developed to be asked to students in the interviews. Work-group of the research was formed with senior year Physics Teaching department students and senior year Sciencs Teaching department students studying at two different university in Turkey. The interviews with each group lasted for 80-90 minutes. During the interviews, a 10-15 minute break was given in the middle of the interview. Teacher candidates were offered treats so that they felt comfortable during the interviews. Before the interviews, the groups were informed that the recordings of the interviews wouldn't be shared with third parties, so that they can answer questions comfortably. The interviews were video-recorded. Seven focus groups were formed. Each focus group included six students, and a total of 42 teacher candidates participated in the present research. Each focus group was numbered from 1 to 7 , and each participant was numbered from 1 to 42 . Information on the focus groups created is given in the Table I below. Common attitude, thought and idea-based deductions were made from the obtained data. When there were different ideas and attitudes were among the group, the answers of the participants in that group were classified, and the numbers of the similar answers were stated. Misconceptions were detected from the answers of the groups.

During these interviews with teacher candidates, further questions were asked in order to determine why they had the misconceptions, and what their answers were based on. This way, the researchers tried to determine why the participants had those misconceptions. The interviews showed that, teacher candidates had misconceptions. In order to correct these misconceptions, conceptual change texts were developed in accordance with the questions used in the interviews. Finally, simulations on events related buoyancy in liquids were offered for teacher and student use.

\section{Instrument}

Six basic questions were developed in order to determine how teacher candidates perceived buoyancy in liquids related events and any misconceptions they had on the subject matter. These questions were used in focus group interviews. The content of these 6 questions is as follows:

Table 1: Information on the focus groups created

\begin{tabular}{lll}
\hline Department & Focus Groups & Participant Numbers \\
\cline { 2 - 2 } Focus 1 & $1,2,3,4,5,6$ \\
& Focus 2 & $7,8,9,10,11,12$ \\
& Focus 3 & $13,14,15,16,17,18$ \\
& Focus 4 & $19,20,21,22,23,24$ \\
Science Teaching & Focus 5 & $25,26,27,28,29,30$ \\
& Focus 6 & $31,32,33,34,35,36$ \\
& Focus 7 & $37,38,39,40,41,42$ \\
\hline
\end{tabular}

- Teacher candidates were first asked for the definition of buoyancy in liquids. With this question, the researchers tried to determine if teacher candidates made the mistake commonly made in textbooks.

- For the second question, the participants were asked how they perceived the state in which an object was floating partially sunk in a vessel filled with liquid. The object was partially sunk, and in balance. Participants were asked what the conditions were for the object's position in the liquid. The important issue in this question was, whether the participants knew what forces affected the object, how to compare these forces, and what was the net force affecting the object.

- For the third question, the participants were asked how they perceived the state in which the object was totally in the liquid but not at the bottom, suspending in the liquid in a vessel. The object is floating totally sunk in the liquid, but suspending in the middle. What is important in this question is whether participants knew what forces affected the object, how to compare the forces, and the net force affecting the object.

- For the fourth question, the participants were asked how they perceived an object sunk to the bottom of a liquid in a vessel. They were asked what were the conditions for the object to be sunk to the bottom. What is important in this question is whether participants knew what forces affected the sunk object, how to compare the forces, and the net force affecting the object.

- In the present research, buoyancy in liquids related events were asked from different points of views. For this reason, a partially sunk floating object was sunk in the water to a certain point. The object, which was sunk to a certain deepness, and staying there with an external force, became free after the external force was released. In this question, the participants were asked how the object would move, and how that movement would end. Additionally, they were asked what forces affected the object during and after the movement, and to compare these forces.

- Finally, they were asked what would happen, if an experiment on buoyancy in liquids conducted on earth were done in a shuttle resting on the moon surface. The perceptions of teacher candidates of buoyancy in such a condition were determined.

\section{FINDINGS}

The answers of the participants to six basic questions asked in focus group interviews with teachers, and the exploratory questions asked in accordance with their answers are presented below respectively. In order to get detailed answers to the questions, the participants were asked further exploratory questions. This way, researchers tried to reveal teacher candidates' perceptions of the physical events completely. 
Below are the numbers of the repetitive answers to the questions in groups in tables.

\section{A. Findings on the 1st basic question asked to focus groups and related exploratory questions:}

The first question asked to teacher candidates in focus group interviews is as follows:

"Can you describe buoyancy in liquids? What is buoyancy in liquids?"

The 4th and 7th focus groups made the following correct definition by specifying the direction of the buoyancy force.

- The upward force exerted on an object by the liquid is called the buoyant force. The magnitude of the buoyant force is equal to the weight of the fluid displaced by the object

The answers of other participants to this question are as follows:

- Buoyancy force affecting an object is equal to the weight of the liquid overflowed as much as the volume of the sunk part."

- Buoyancy force affecting an object is equal to the weight of the water displaced as the volume of the sunk part of the object.

Teacher candidates were asked if they were certain of their answers. All of them stated that they were sure of their answers. Teacher candidates were asked what they based their answers on and where they learnt this information. All of the candidates offered the following justifications:

- "Buoyancy in liquids is defined this way in textbooks."

- "Teachers in private course define it this way, and the books of these courses provide the same definition."

These answers are almost the same, and generally their definitions were almost the same with the definitions in the books. Following these answers, the groups were asked the following related question:

"You stated that you were certain of your answer. You stated that the buoyancy force affecting an object was equal to the weight of the displaced (overflowed) liquid. If these two forces are equal, are the directions of the buoyancy force affecting the object, and the displaced (overflowed) liquid the same?"

With this question, arguments started in interviewed focus groups. During the observations, some groups started a heated debate. With this question, disagreements started within the focus groups.

Interestingly, 9 of the students claimed that the definition was indisputable, therefore the directions of the buoyancy and the displaced (overflowed) liquid were the same. On the other hand, 21 of the students argued that the definition was inadequate, the quantities of buoyancy and the weight of the displaced liquid were the same, but their directions were opposite. However, these 21 teacher candidates couldn't persuade all the other of the members of their groups.
Table 2: Numbers of the repetitive correct and wrong answers to the 1st question

$\begin{array}{ll}\text { Wrong answers number } & \text { Correct answers } \\ \text { of repetitions } & \text { number of repetitions } \\ \text { (students number) } & \text { (students number) }\end{array}$

\begin{tabular}{lll} 
Focus Groups & (students number) & (students number) \\
\hline Focus 1 & & 5 \\
Focus 2 & 5 \\
Focus 3 & $3 \quad(13,14,15)$ \\
Focus 4 & 6 \\
Focus 5 & 4 \\
Focus 6 & 4 \\
Focus 7 & 6 \\
Total $(\%)$ & $9(\% 21)$ & $33(\% 79)$ \\
\hline
\end{tabular}

Consequently, teacher candidates claiming that buoyancy force and the weight of the displaced (overflowed) liquid were the same were mistaken seriously. The numbers of the repetitive correct and wrong answers given by the teacher candidates by groups are presented in Table 2 .

The answers to the first question indicate how teacher candidates were affected from the definitions. $21 \%$ of the participants claimed that their definitions were correct as they were the same with the textbooks, and the directions of the buoyancy and the displaced (overflowed) liquid should be the same. This finding is also important in terms of epistemological beliefs of teacher candidates. Teacher candidates claimed that they were sure of the correctness of the information in the textbooks again and again. They never doubted the absolute correctness of the information given in the books. The rest $50 \%$ of the participants claimed that they were sure of the correctness of the definition at first, but they changed their minds with the exploratory question. These participants claimed that the quantity of the buoyancy in the liquids and the weight of the displaced (overflowed) liquid were the same, but their directions were opposite. However, these participants couldn't persuade the other teacher candidates in their groups.

\section{B. Findings on the 2 nd basic question asked to focus groups and related exploratory questions:}

The second question asked to teacher candidates in focus group interviews is as follows:

"As shown in Figure 1, the object floats on the liquid in a vessel, partially sunk. What is the condition for this state of the object?"

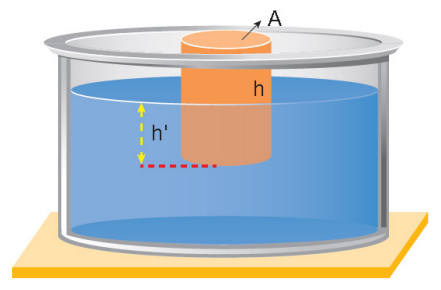

Fig. 1: Visual for the 2nd question asked to participants 
All of the teacher candidates in focus groups answered the 2 nd question correctly. Their answer was:

- The intensity of the object should be less than the density of the liquid for the object to float."

After their answers, the following exploratory question was asked to focus groups in accordance with the purpose of the second question:

"Can you draw what forces affect an object in partially sunk state, and tell the net force affecting the object?"

While answering this question, the participants drew an upward arrow for buoyancy force affecting the object, and a downward arrow for the weight of the object. Naturally, discussions started in some groups with this answer. Because, for the 1st question, $21 \%$ of the participants claimed that the directions of these forces were the same. With this question, the rest of the teacher candidates also changed their minds and claimed that the directions were opposite.

After drawing the forces, participants were asked to compare the quantities of the forces, and gave two different answers for the net force affecting the object. One of these was correct, and the other was not. Participants were asked for their justifications for their answers. Correct and wrong answers with their justifications are presented below, respectively:

- Wrong answer given by teacher candidates was;

"Buoyancy force affecting the object is greater than the weight of the objects, and their directions are opposite. In this case, an upward net force affects the object."

Their justification for this answer was;

"For the object to be out of water partially, the upward buoyancy force should be greater than the weight of the object."

- Correct answer given by teacher candidates was;

"The quantity of buoyancy force affecting the object is equal to the weight of the object. As the directions

Table 3: Numbers of the repetitive correct and wrong answers to the 2 nd question

\begin{tabular}{|c|c|c|c|}
\hline $\begin{array}{l}\text { Focus } \\
\text { groups }\end{array}$ & & $\begin{array}{l}\text { Wrong answers } \\
\text { number of repetitions } \\
\text { (students number) }\end{array}$ & $\begin{array}{l}\text { Correct answers } \\
\text { number of } \\
\text { repetitions (students } \\
\text { number) }\end{array}$ \\
\hline Focus 1 & 4 & & $2 \quad(4,5)$ \\
\hline Focus 2 & 4 & & $2 \quad(8,9)$ \\
\hline Focus 3 & 3 & & $3(13,14,15)$ \\
\hline Focus 4 & 3 & & $3 \quad(19,20,24)$ \\
\hline Focus 5 & $\begin{array}{l}1 \\
(25)\end{array}$ & & 5 \\
\hline Focus 6 & 6 & & --------- \\
\hline Focus 7 & $\begin{array}{l}1 \\
(41)\end{array}$ & & 5 \\
\hline Total (\%) & & $22(\% 52)$ & $20(\% 48)$ \\
\hline
\end{tabular}

of these two forces are opposite, net force is neutral." Their justification for their answer was; "If the net force affecting the object wasn't neutral, the object would move." The numbers of teacher candidates answering the exploratory question correctly and wrong by focus groups are presented in Table 3. Accordingly, 52\% of the participants gave wrong answers. All of the participants in focus group 6 answered incorrectly. Therefore, teacher candidates have difficulties in understanding this physical event, and have misconceptions about it.

$48 \%$ of the participants drew the forces affecting a partially sunk object correctly, and showed that the net force affecting the object was neutral. These participants couldn't persuade the other members of their groups on the correct answer.

\section{Findings on the 3rd basic question asked to focus groups and related exploratory questions:}

The third question asked to teacher candidates in focus group interviews is as follows:

"What is the condition for the object to suspend in the water as shown in Figure 2?"

All of the teacher candidates in focus groups answered the $3 \mathrm{rd}$ question correctly. Their answer was:

- For the object to suspend in the water as in the figure, the densities of the object and the liquid should be the same."

After their answers, the following exploratory question was asked to focus groups in accordance with the purpose of the third question:

"Can you draw what forces affect an object suspending in a liquid, and tell the net force affecting the object?"

All of the participants answered this question correctly. After drawing the forces affecting the object on the figure, the compared the quantities of these forces, and gave the following answer:

- "The quantity of the buoyancy force affecting the object is equal to the quantity of the weight of the object. Because the directions of these two forces opposite, the net force affecting the object is neutral."

Their justification for this answer was;

"If the force affecting the object were not neutral, the object would move. The object would either go up, or sink."

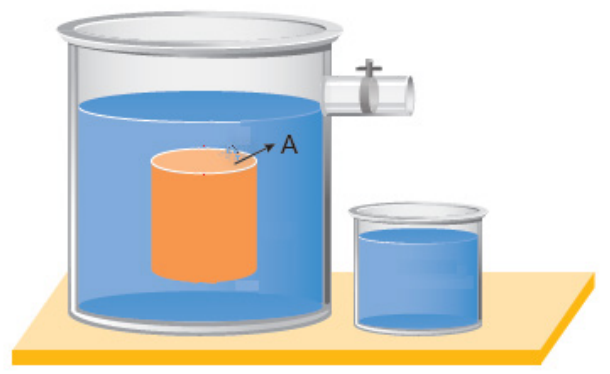

Fig. 2: Visual for the 3rd question asked to participants 
The numbers of repetitive correct answers of the groups are shown in Table 4.

\section{Findings on the 4th basic question asked to focus groups and related exploratory questions:}

The fourth question asked to teacher candidates in focus group interviews is as follows:

"What is the condition for the object to sink to the bottom

of a vessel filled with liquid as shown in Figure 3?"

All of the teacher candidates in focus groups answered the $3 \mathrm{rd}$ question correctly. Their answer was:

For the object sink to the bottom of the vessel and stay sunk on the bottom as in the figure, the density of the object should be less than the density of the liquid.

After their answers, the following exploratory question was asked to focus groups in accordance with the purpose of the fourth question:

"Can you draw what forces affect an object sunk to the bottom in a liquid, and tell the net force affecting the object?"

After drawing the forces, participants were asked to compare the quantities of the forces, and gave two different answers for the net force affecting the object. One of these was correct,

Table 4: Numbers of the repetitive correct and wrong answers to the 3 rd question

\begin{tabular}{|c|c|c|c|}
\hline $\begin{array}{l}\text { Focus } \\
\text { Groups }\end{array}$ & & $\begin{array}{l}\text { Wrong } \\
\text { Answers } \\
\text { Number Of } \\
\text { Repetitions }\end{array}$ & $\begin{array}{l}\text { Correct Answers } \\
\text { Number Of } \\
\text { Repetitions (Students } \\
\text { Number) }\end{array}$ \\
\hline Focus 1 & $\ldots \ldots \ldots$ & & 6 \\
\hline Focus 2 & ......... & & 6 \\
\hline Focus 3 & ......... & & 6 \\
\hline Focus 4 & $\ldots \ldots \ldots$ & & 6 \\
\hline Focus 5 & $\ldots \ldots \ldots$ & & 6 \\
\hline Focus 6 & $\ldots \ldots \ldots$ & & 6 \\
\hline Focus 7 & $\ldots \ldots \ldots$ & & 6 \\
\hline Total (\%) & & ......... & $42(\% 100)$ \\
\hline
\end{tabular}

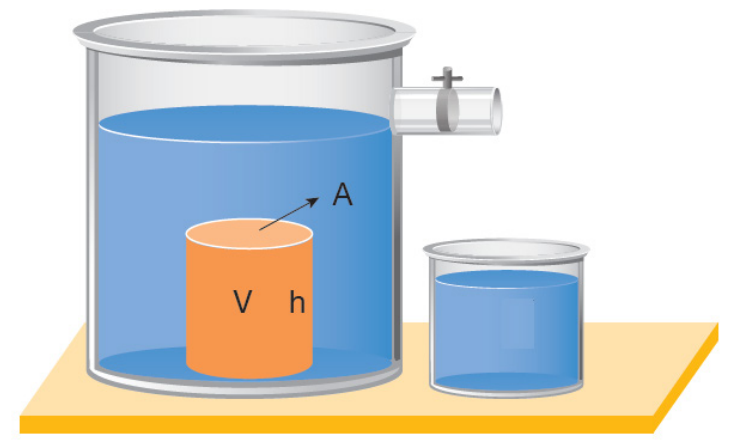

Fig. 3: Visual for the 4th question asked to participants and the other was not. Participants were asked for their justifications for their answers. Correct and wrong answers with their justifications are presented below, respectively:

- Wrong answer given by teacher candidates was; "There are two forces affecting the object. These forces are buoyancy force and the weight of the object. Weight of the object affecting it downward is greater than the buoyancy force affecting it upward. Therefore, the net force affecting the object is downward."

Their justification for their answer was;

"The only way for the object stay on the bottom of the vessel filled with liquid is that the weight of the object is greater than the buoyancy force."

These participants couldn't answer why the object stayed on the bottom while a net force was affecting it.

- Correct answer given by teacher candidates was;

"There are three forces affecting the object. These are; upward buoyancy force, downward weight of the object, and the upward reaction force from the bottom of the vessel to the object. The quantity of the buoyancy force affecting the object is less than the weight of the object. Reaction force from the bottom balanced the difference. In this case, the net force affecting the object is neutral."

Their justification for this answer was;

"If the force affecting the object weren't neutral, the object would move."

The numbers of participants answering the exploratory question correctly and incorrectly by focus groups are shown in Table 5. As can be seen in the table, $29 \%$ of the participants answered the question incorrectly. All of the teacher candidates in 1st and 6th focus groups answered the question incorrectly. Accordingly, teacher candidates have difficulty in understanding this physical event and have misconceptions about it.

$71 \%$ of the participants showed the forces affecting an object sunk to the bottom of a vessel filled with liquid correctly, and stated the net force affecting the objects was neutral.

Table 5: Numbers of the repetitive correct and wrong answers to the 4 th question

\begin{tabular}{|c|c|c|c|}
\hline $\begin{array}{l}\text { Focus } \\
\text { groups }\end{array}$ & & $\begin{array}{l}\text { Wrong answers } \\
\text { number of } \\
\text { repetitions }\end{array}$ & $\begin{array}{l}\text { Correct answers } \\
\text { number of repetitions } \\
\text { (students number) }\end{array}$ \\
\hline Focus 1 & 6 & & $\ldots \ldots$ \\
\hline Focus 2 & $\ldots \ldots$ & & 6 \\
\hline Focus 3 & & & 6 \\
\hline Focus 4 & $\ldots \ldots$ & & 6 \\
\hline Focus 5 & $\ldots \ldots$ & & 6 \\
\hline Focus 6 & 6 & & $\ldots \ldots$ \\
\hline Focus 7 & $\ldots \ldots$ & & 6 \\
\hline Total (\%) & & $12(\% 29)$ & $30(\% 71)$ \\
\hline
\end{tabular}




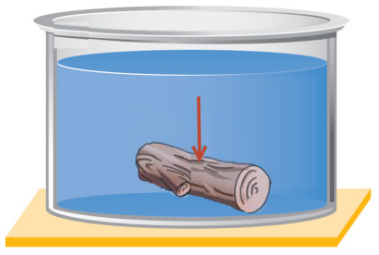

Fig. 4: Visual for the 5th question asked to participants

In these focus groups, there were some teacher candidates who answered the question incorrectly. However, the other members giving the right answer persuaded these easily.

\section{E. Findings on the 5th basic question asked to focus groups and related exploratory questions:}

The fifth question asked to teacher candidates in focus group interviews is as follows:

"As shown in Figure 4, we push a piece of wood floating on the surface of the water down to the bottom with our hand. When we release the piece of wood, how will it move, and how will the movement end? Explain the forces affecting the piece of wood."

Focus groups gave different answers to this question. However, all focus groups gave the same answers for the part until the wood block reaches the surface. In this part, participants asked whether there was friction. They were told that there was friction, even little, due to viscose of water. Accordingly, the answer given by the focus groups for the part until the wood block reaches the surface is follows:

"When the wood block is released, it will accelerate upward with the upward net force, as the upward buoyancy force is greater than the downward weight and the friction force."

All of the teacher candidates gave correct answers for the part the object starts to reach the surface. However, the answers varied for the second part of the movement. The groups gave different answers for the part the object surfaces. Additionally, there were different answers within the groups. One of these answers was wrong. And the other was accepted as correct as it was almost correct. The fully correct answer was given by the four participants in focus group 4. Below are the wrong answer, almost correct answer, and the exact correct answer given by the focus group 4 . In the table, almost correct answers were accepted as correct.

- The wrong answer given by the participants was;

"Wood block starts to surface. The movement continues until the object surfaces partially. Then, it stops. The object stays this way, as the buoyancy is greater than the weight of the object."

Their justification for this answer was;

"In the end, part of the object will be out of the water when it stops. For the object to stay this way, the upward buoyancy force should be greater than the weight of the object."
- The almost correct answer given by the participants (accepted as correct) is;

"As the object starts surfacing the quantity of the buoyance force decreases and when it is equal to the quantity of the weight, the wood block stays on surface partially in the water."

Their justification for this answer was;

"When the wood block surfaces, net force affecting it will be neutral. Because, the quantity of the buoyance affecting the object upward equals to the quantity of the weight affecting it downward."

- The exact correct answer given by focus group 4 was; "As the object starts surfacing, the quantity of the buoyance force decreases and the weight becomes greater than it. For this reason, the wood block slows down, stops, and accelerates a little downward. But this time, buoyance becomes greater. Wood block makes a damped harmonic move and stops. It floats on the surface partially in the water. When the object stops, the net force affecting it becomes neutral, and the quantities of buoyance force and the weight of the wood block become equal."

The numbers of repetitive correct answers of the groups are shown in Table 6.

\section{F. Findings on the 6th basic question asked to focus groups and related exploratory questions:}

The fifth question asked to teacher candidates in focus group interviews is as follows:

As shown in Figure 5, in an experiment conducted on earth, an object is dropped in water and it sinks to the bottom. The object is 1.5 times denser than the water. If the same experiment were conducted on the surface of the moon, where the gravitational acceleration is the 1/6 of the earth, what would you say about the floating, suspending, or sinking of the object?

Table 6: Numbers of the repetitive correct and wrong answers to the 5 th question

\begin{tabular}{|c|c|c|c|}
\hline $\begin{array}{l}\text { Focus } \\
\text { groups }\end{array}$ & & $\begin{array}{l}\text { Wrong answers } \\
\text { number of } \\
\text { repetitions } \\
\text { (students number) }\end{array}$ & $\begin{array}{l}\text { Correct answers } \\
\text { number of } \\
\text { repetitions } \\
\text { (students number) }\end{array}$ \\
\hline Focus 1 & 4 & & $2(4,5)$ \\
\hline Focus 2 & 4 & & $2(8,9)$ \\
\hline Focus 3 & 3 & & $3(13,15,17)$ \\
\hline Focus 4 & $\begin{array}{l}2 \\
(22,23)\end{array}$ & & 4 \\
\hline Focus 5 & $1(30)$ & & 5 \\
\hline Focus 6 & 6 & & $\ldots \ldots$ \\
\hline Focus 7 & $1(41)$ & & 5 \\
\hline Total (\%) & & $21(\% 50)$ & $21(\% 50)$ \\
\hline
\end{tabular}


Two of the focus groups answered this question correctly. One of the participants in each of these two groups persuaded the other members and they gave the correct answer. These are participant number 4 in group number 1 , and the participant number 13 in group number 3 . The mistakes made answering this question were all the same. The correct and wrong answers given to this question are below with their justifications.

- The wrong answer given by teacher candidates was; "As the weight of the object would be less on moon surface, the object would start to float. As the liquid is the same, buoyancy would not change. Because, the density would be the same. The quantity of the weight of the object would be 1/6 of its weight on earth. In this case, the buoyancy force would be greater than the weight of the object. Consequently, the object would float."

- The correct answer given by teacher candidates was; "The weight of the object would be less than its weight on earth. However, the quantity of the buoyancy force of water would be less than it is on earth. Because, quantity of buoyance force is equal to the weight of displaced liquid. Accordingly, the quantity of displaced liquid would decrease equally. Consequently, the object would sink the same way."

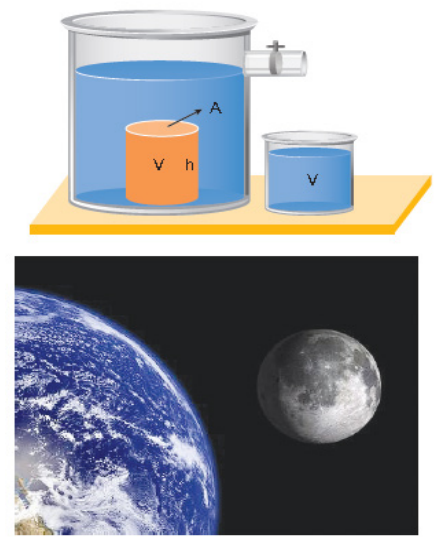

Fig. 5: Visual for the 6th question asked to participants

Table 7: Numbers of the repetitive correct and wrong answers to the 6 th question

\begin{tabular}{|c|c|c|c|}
\hline Focus groups & & $\begin{array}{l}\text { Wrong answers } \\
\text { number of } \\
\text { repetitions }\end{array}$ & $\begin{array}{l}\text { Correct answers } \\
\text { number of } \\
\text { repetitions }\end{array}$ \\
\hline Focus 1 & ...... & & 6 \\
\hline Focus 2 & 6 & & $\ldots \ldots$. \\
\hline Focus 3 & $\ldots \ldots$ & & 6 \\
\hline Focus 4 & 6 & & \\
\hline Focus 5 & 6 & & \\
\hline Focus 6 & 6 & & \\
\hline Focus 7 & 6 & & \\
\hline Total (\%) & & $30(\% 71)$ & $12(\% 29)$ \\
\hline
\end{tabular}

The numbers of repetitive correct answers of the groups are shown in Table 7 .

\section{Conclusion And Discussion}

Misconceptions and misunderstandings teacher candidates have, in accordance with the findings obtained during focus group interviews can be listed as follows:

1. All of the participants defined buoyancy force as "Buoyancy force affecting an object in a still liquid is equal to the weight of displaced liquid". However, directions of these two forces are opposite. This definition is deficient from one aspect. Teacher candidates were asked about the directions of these forces in accordance with their definitions, and $9(21 \%)$ of them claimed they should be the same in accordance with the definition. This answer created disagreements within groups.

2. Teacher candidates were asked about the forces affecting an object floating on a still liquid, partially in the liquid, and they were asked to compare the forces affecting such an object. 22 (52\%) of them stated that "Buoyancy force affecting the object should be greater than the weight of the object and the directions of these forces should be opposite". However, this explanation is incorrect because the object is still. The net force affecting an object floating still on the surface of water is neutral.

3. The pre-service teachers were asked about the forces acting on an object suspended in a liquid.Pre-service teachers did not make any mistakes in this question. The suspension of the object in the liquid is easier to understand than other situations.

4. Focus groups were asked about the forces affecting an object sunk to the bottom of a vessel filled with liquid, and what the net force affecting the object was. 12 (29\%) of the participants said "There are two forces affecting the object. Weight of the object affecting it downward is greater than the buoyance force affecting it upward. So the net force affecting the object is downward. However, there are three main forces affecting such an object. Teacher candidates didn't take the upward reaction force from the bottom of the vessel balancing the object into account. The acting forces should be shown as in Figure 6 .

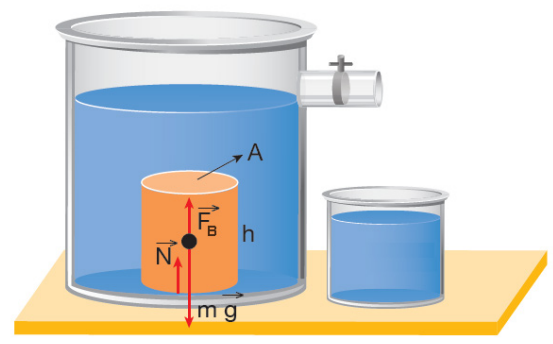

Fig. 6: Visual regarding the answer to the 3rd question asked to the participants. 


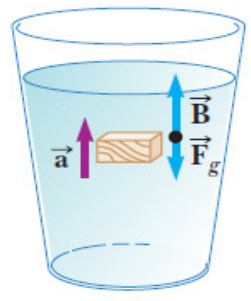

(a)

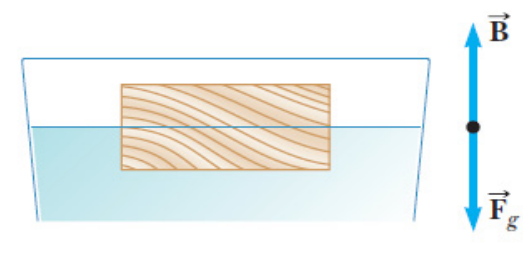

(b)
Fig. 7. a) A totally submerged object that is less dense than the fluid in which it is submerged experiences a net upward force. b) When the object begins to float, the magnitude of the buoyancy force becomes equal to the magnitude of the object's weight.

5. Focus groups were asked about the movements of a piece of wood sunk into the water with an external force. 21 (50\%) of participants explained the movement as the piece of wood surfaces incorrectly. They stated that, even when the wood block surfaced and stopped, upward buoyance affecting the object was greater than the downward force of the weight of the object. For this question, they could take viscose into account. But they couldn't explain that the object would make a damped oscillation movement as it surfaced. During the short-term oscillation on the surface of the water, the buoyance will become greater as the object gets into water, and it will become less when it surfaces until this damped movement ends. The pre-service teachers could not explain that the buoyancy force would decrease as the object came out of the water. A brief explanation on this subject is given in Figure 7.

6. $30(71 \%)$ of the participants claimed that, an object 1.5 times denser than the water sinking on the earth, would float on moon surface where gravitational acceleration is $1 / 6$ of the earth. However, as the weight of the object decreases on the moon, the quantity of the buoyance of water decreases as well. Because, as the gravitational acceleration of the planet changes, liquid pressure changes as well, which will change the pressure difference on the object in the liquid.

By comparing the results of the research with other studies, similar situations and situations that differ from other studies were tried to be revealed. As the findings obtained in the present research suggest, teacher candidates have certain misconceptions and misunderstandings of the buoyance force. There may be various reasons underlying these. The starting point of the research was the thought that wrong definitions could have an effect on the misunderstandings of teacher candidates. Many researches claim that, previous knowledge and epistemological beliefs teacher candidates and students have while learn concepts related to physics have great effect (Bozkurt, \& Ilik, 2010; Zeineddin, \& AbdEl-Khalick, 2010; Hammer, 1994). The present research also found that epistemological beliefs of teacher candidates were very effective. The interviews with teacher candidates revealed that, they were certain of the correctness of the information in textbooks, and they didn't question these.

Studies mostly deal with situations where the density of the liquid is compared with the density of the object in order to determine the floating or sinking states of the objects (She, 2002; Kawasaki, Herrenkohl, \& Yeary, 2004; Shen, Liu, \& Chang, 2015). However, this comparison is not effective enough in our study. Pre-service teachers have misconceptions when comparing the forces acting on objects, especially in swimming and sinking situations. Some studies show that students reason by talking about balanced and unbalanced forces in order to understand the subject of swimming and sinking (Moore \& Harrison, 2004). In this study we have done, pre-service teachers are in error by saying that the buoyancy force acts with a greater force than the weight of the object while floating, and that there is a net force on the object (Fig. 1). Another result found in this study, which is different from other studies, is related to the forces acting on a sinking object. Pre-service teachers say that there is a net force acting on a sinking object at the bottom of the container. They thought that the object sunk into the bottom of the container was under the influence of an unbalanced force.

Studies have questioned the relationship between the weight of the liquid displaced by the objects and the magnitude of the buoyancy force (Cepni and Şahin, 2012; She, 2002; Hewit, 2002: Yin, Tomita, and Shavelson, 2008). In this study, unlike other studies, the sinking of a floating object with the help of an external force was investigated (Fig. 4). When the external force on this object is removed, the motion of the object was questioned. Most of the pre-service teachers started to explain by using the assumption that the buoyant force acting on the object while floating is greater than the weight of the object. They did not state that the buoyant force acting on the object would increase while it was being immersed. However, they stated that it will have a constant acceleration as it goes up in the liquid. Viscosity status was not questioned in this study. This situation was expected from the students. There are teacher candidates who do not know or cannot understand that the magnitude of the buoyancy force should change from the moment the object starts to come out of the water surface. Pre-service teachers answered this question from a different perspective. It is thought that they give their answers by generalizing a situation they know to a different situation. The overgeneralization here causes misunderstandings of teacher candidates.

Finally, in this study, another situation that is different from other studies is mentioned. Answers were sought to the question of what would happen if the experiments on buoyancy were repeated on a planet where the gravitational acceleration was different. Some pre-service teachers said that a sinking object can float with the change in gravitational 
acceleration. The pre-service teachers thought that there would be no change in the buoyancy force with the change of the gravitational acceleration. However, with the change of gravitational acceleration, the weight of the displaced fluid will also change. Also, changing the gravitational acceleration will also change the fluid pressure. Pre-service teachers gave answers by thinking that only the weight of the object in the liquid would change. The fact that pre-service teachers only think object-oriented is an indication that they have misunderstandings.

For a better understanding of buoyance force in liquids, the starting point should be the fact that buoyance force is a result of difference between pressures. Interviews showed that teacher candidates, who participated in the present research didn't know this fact. Additionally, textbooks should include the information about how buoyance in liquids changes on different planets with different gravitational acceleration.

Many studies have shown that computer simulations and augmented reality applications positively affect students' physics and science learning (Bozkurt \& Ilik, 2010; Yildirim, 2020; Yildirim, 2021; Simanjuntak, Hutahaean, Marpaung, \& Ramadhani, 2021). An effective simulation, which can be used to teach buoyance in liquids, was already developed by PHET group. Using this simulation, events related to buoyance force can be taught easily. However, the simulation doesn't include the reaction force from the bottom when a wooden block is sunk into the bottom of a pool with an external force. The same experiment can be demonstrated to students using real materials in a classroom setting.

\section{References}

Bozkurt, E., \& Ilik, A. (2010). The effect of computer simulations over students' beliefs on physics and physics success. Procedia-Social and Behavioral Sciences, 2(2), 4587-4591.

Çepni, S. \& Şahin, C. (2012). effect of different teaching methods and techniques embedded in the 5e instructional model on students' learning about buoyancy force. Eurasian Journal of Physics \& Chemistry Education, 4(2), 97-127.

Eryilmaz, A. (2002). Effects of conceptual assignments and conceptual change discussions on students' misconceptions and achievement regarding force and motion. Journal of research in science teaching, 39(10), 1001-1015.

Hammer, D. (1994). Epistemological beliefs in introductory physics. Cognition and instruction, 12(2), 151-183.

Hammer, D. (1995). Epistemological considerations in teaching introductory physics. Science Education, 79, 393-413.

Hewson, M. G., \& Hewson, P. W. (1983). Effect of instruction using students' prior knowledge and conceptual change strategies on science learning. Journal of Research in Science Teaching, 20(8), 731-743.
Hung, W., Jonassen, D.H. (2006). Conceptual understanding of causal reasoning in physics. International Journal of Science Education, 28(13), 1601 - 1621.

Kawasaki, K., Herrenkohl, L. R. \& Yeary, S. A. (2004). Theory building and modeling in a sinking and floating unit: a case study of third and fourth-grade students' developing epistemologies of science, International Journal of Science Education, 26(11), 1299-1324.

Linder, C.J. 1992. Is teacher-reflected epistemology a source of conceptual difficulty in physics? International Journal of Science Education 14: 111-21.

Lising, L., and A. Elby 2005. The impact of epistemology on learning: A case study from introductory physics. American Journal of Physics 73, no. 4: 372-82.

Moore, T. \& Harrison, A. (2004). Everyday Science in middle school: Floating and sinking concepts. AARE Annual Conference, Melbourne.

Özsevgeç, T. \& Çepni, S. (2006). Students' understanding levels floating and sinking concepts in different grade. Journal of National Education (Milli Eğitim Dergisi), 172, 297-311.

Şahin, Ç. \& Çepni, S. (2011). Developing of the concept cartoon, animation and diagnostic branched tree supported conceptual change text: "Gas pressure". Eurasian J. Phys. Chem. Educ.,Special Issue, 25-33.

She, H.C. (2002). Concepts of a higher hierarchical level require more dual situated learning events for conceptual change: A study of air pressure and buoyancy. International Journal of Science Education, 24(9), 981-996, DOI: 10.1080/09500690110098895.

Shen, J., Liu, O. L., \& Chang, H. Y. (2015). Assessing students' deep conceptual understanding in physical sciences: an example on sinking and floating. International Journal of Science and Mathematics Education, Advance online publish, doi:10.1007/ s10763-015-9680-z.

Simanjuntak, M. P., Hutahaean, J., Marpaung, N., \& Ramadhani, D. (2021). Effectiveness of problem-based learning combined with computer simulation on students' problem-solving and creative thinking skills. International Journal of Instruction, 14(3), 519-534.

Tural, G., Akdeniz, A.R. \& Alev, N. (2010). Effect of 5E teaching model on student teachers' understanding of weightlessness. Journal of Science Education and Technology, 19(5), 470-488.

Yildirim, F. S. (2020). The effect of the augmented reality applications in science class on students' cognitive and affective learning. Journal of Education in Science Environment and Health, 6(4), 259-267.

Yildirim, F. S. (2021). Effectiveness of augmented reality implementation methods in teaching Science to middle school students, International Journal of Curriculum and Instruction, vol. 13, no. 2, pp. 1024-1038.

Yin, Y., Tomita, M.K. \& Shavelson, R.J. (2008). Diagnosing and dealing with student misconceptions: Floating and sinking. Science Scope,31(8), 34-39.

Zeineddin, A., \& Abd-El-Khalick, F. (2010). Scientific reasoning and epistemological commitments: Coordination of theory and evidence among college science students. Journal of Research in Science Teaching, 47(9), 1064-1093. 